\title{
Prospective comparison of double contrast barium enema plus flexible sigmoidoscopy $v$ colonoscopy in rectal bleeding: barium enema $v$ colonoscopy in rectal bleeding
}

\author{
E JAN IRVINE, JOANNE O'CONNOR, R A FROST, P SHORVON, \\ S SOMERS, G W STEVENSON, AND R H HUNT
}

From the Departments of Gastroenterology and Radiology McMaster University Medical Centre, Hamilton, Ontario, Canada

SUMmaRy Rectal bleeding often heralds serious colonic disease. The literature suggests that colonoscopy is superior to barium enema plus sigmoidoscopy, although no good comparative studies exist. Seventy one patients with overt rectal bleeding had prospectively flexible sigmoidoscopy, double contrast barium enema and colonoscopy completed independently. Against the gold standard, the sensitivity and specificity of colonoscopy were 0.69 and 0.78 respectively for a spectrum of colonic lesions, while for combined flexible sigmoidoscopy and double contrast barium enema these values were 0.80 and 0.56 , respectively. When assessing adenoma or carcinoma, colonoscopy was more sensitive at 0.82 v 0.73 , while flexible sigmoidoscopy plus double contrast barium enema was superior for detecting diverticular disease. The positive predictive value for colonoscopy was 0.87 against 0.81 for flexible sigmoidoscopy and double contrast barium enema. This study confirms that colonoscopy should be a first line investigation in subjects likely to require biopsy or therapeutic intervention.

Rectal bleeding is frequently associated with serious colonic pathology. ${ }^{1-3}$ Patients referred to the gastroenterologist with this symptom are diagnosed to have anal disease alone in approximately $20 \%, 25 \%$ have clinically important lesions such as adenoma, adenocarcinoma, diverticular disease, inflammatory bowel disease or angiodysplasia, and another $25 \%$ have combined anal and important disease. Thirty per cent will have no cause of bleeding identified. ${ }^{2+9}$

Traditionally, the investigation of rectal bleeding has been by sigmoidoscopy and barium enema followed by colonoscopy if symptoms persisted despite a negative examination or if the barium enema was technically inadequate. ${ }^{10}$ Specific indica-

Address for correspondence: Dr E Jan Irvine, Division of Gastroenterology, Rm 4W8-HSC, McMaster University, 1200 Main St W, Hamilton, Ontario, Canada, L8N $3 Z 5$.

Received for publication 7 April 1988. tions for colonoscopy were biopsy of a particular lesion or polypectomy.

More recently, physicians are promoting colonoscopy as the initial investigation for patients with rectal bleeding. Evidence supporting this recommendation, however, comes from retrospective studies $^{510-14}$ comparing high quality endoscopy with average radiology ${ }^{10} 15-18$ in selected patient populations. ${ }^{516} 18-21$

Prospective studies comparing flexible sigmoidoscopy or double contrast barium enema $v$ colonoscopy have also been biased by inequality of expertise of radiology and endoscopy. For example, four prospective comparative studies used colonoscopy as the gold standard of diagnosis. ${ }^{681622}$ Such a design would dictate that colonoscopic false positives be interpreted as radiologic false negatives and colonoscopic false negatives be interpreted as barium study 
false positives. These errors reduce the sensitivity and specificity of the barium enema.

These intrinsic biases in the test evaluations justified this prospective trial in order to compare the diagnostic properties of combined flexible sigmoidoscopy plus double contrast barium enema versus colonoscopy in a cohort of patients with overt rectal bleeding.

\section{Methods}

\section{PATIENTS}

Between August 1985, and December 1986, all patients referred to McMaster University Medical Centre for investigation of rectal bleeding by double contrast barium enema or colonoscopy were approached. Subjects were considered eligible if they had passed red blood per rectum within the previous three months and in a subset who were hospitalised, had no postural hypotension $\geq 20 \mathrm{~mm}$ or transfusion requirement of more than 2 units of packed red blood cells. Those who had a history of melaena stools alone, occult bleeding or a contraindication to either procedure were excluded. The cohort which consented underwent flexible sigmoidoscopy immediately before double contrast barium enema, followed within two weeks by colonoscopy. Each procedure was carried out by a different consultant endoscopist or radiologist after rapid colonic lavage preparation (Golytely, Braintree Laboratories). Procedures were completed in a standard fashion without sedation for the flexible sigmoidoscopy and double contrast barium enema but colonoscopy was preceded by intravenous administration of a meperedine/ diazemuls combination. ${ }^{2324}$ Each examining physician was blinded to all other colonic imaging procedure results. At colonoscopy, however, an unblinded observer was present and a 'staged withdrawal' was undertaken. This required the endoscopist to insert the colonoscope maximally, then withdraw by $10 \mathrm{~cm}$ increments (roughly one segment of colon - for example, descending to sigmoid). Missed pathology was defined only after a lesion had been passed by at least one full colonic segment. The endoscopist was then informed and the instrument reinserted to circumvent the need for subsequent repeat examination. Only the blinded examination results were recorded and a research assistant was present to prevent breech of conduct or 'hinting' at results. In cases where there was discordance of diagnosis between the colonoscopy and other test results, subjects were asked to undergo immediate repeat barium enema which focussed on the controversial segment of bowel. Biopsy was not permitted at flexible sigmoidoscopy because double contrast enema followed immediately, and biopsy or poly-
Table 1 Diagnostic frequencies in 71 study participants

\begin{tabular}{lcccc}
\hline Descriptor & $D X 1$ & $D X 2$ & $D X 3$ & $D X 4$ \\
\hline Cancer & 5 & - & - & - \\
Polyp $\geq 5 \mathrm{~mm}$ & 12 & 3 & - & - \\
$\quad<5 \mathrm{~mm}$ & 7 & 4 & - & - \\
Ischaemia & 1 & - & - & - \\
AVM & 2 & - & 1 & - \\
Endometriosis & - & 1 & - & - \\
IBD & 4 & 2 & - & - \\
DD & 18 & 11 & 4 & - \\
Anal & 12 & 17 & 6 & 3 \\
Volvulus & 1 & - & - & - \\
Normal & 9 & - & - & - \\
Total & 71 & 38 & 11 & 3 \\
\hline
\end{tabular}

$\mathrm{AVM}=$ angiodysplasia $; \mathrm{IBD}=$ inflammatory bowel disease; $\mathrm{DD}=$ diverticular disease.

pectomy was done at colonoscopy if clinically indicated. The extent and quality of examination, any side effects and complications were recorded for each procedure. Furthermore, barium enemas were reread in batches, in a blinded fashion by two observers, three months after the initial procedure. At this time, a third interpretation was made by at least two observers in the light of results of the two endoscopic procedures to highlight any sources of error in $x$-ray interpretation.

An economic assessment of costs and effects as well as assessment of patient preference for procedures was also undertaken and is reported elsewhere. ${ }^{25}$

\section{ANALYSIS OF DATA}

Final diagnoses for each subject were given priority by the lesion's potential gravity, with neoplasms ranking most and anal lesions least serious, as illustrated by diagnosis 1 in Table 1 . Up to three additional diagnoses were made, applying identical ranking rules such as - for example, an individual with a cancer, diverticulosis and haemorrhoids would be classed thus for diagnoses one, two, and three respectively.

For those who completed the study protocol, all had flexible sigmoidoscopy, double contrast enema, colonoscopy plus a repeat interpretation of barium $x$ ray examination at a time remote from the initial reading.

The gold standard consisted of the maximum diagnostic data available for each patient and any lesion (with the exception of haemorrhoids and anal fissures) was required to be reported on at least three test results or be upheld by histology. Each diagnostic test was compared with the gold standard and twoby-two contingency tables were constructed, as shown in the Figure, to permit calculation of the 
diagnostic properties, sensitivity, specificity, positive and negative predictive values and likelihood ratios for positive and negative tests.

This study was approved by the local human research review committee in June 1985.

\section{Results}

PATIENT CHARACTERISTICS

Of 315 eligible subjects, 89 gave informed consent and 71 completed the study. One patient had a myocardial infarction immediately before the flexible sigmoidoscopy, double contrast barium enema combination, possibly as a result of the bowel preparation and two subjects dropped out before flexible sigmoidoscopy. An additional 15 patients refused to undertake colonoscopy because of pain at barium enema (11 patients), reluctance to undertake any additional tests (three patients), or had left the country (one patient). Characteristics of participants, non-participants, and dropouts were similar with respect to age, gender, and final diagnosis. The mean participant's age was 53.5 (16.7) (SD) and 54\% were women. Of eligible candidates, one third were referred by family physicians and two thirds by gastroenterologists or gastrointestinal surgeons. In 32 subjects who had lesions identified and biopsied at colonoscopy, histology was available. Three subjects underwent repeat barium enema because of polyps missed at colonoscopy despite the presence of an unblinded observer. Two patients were required to undergo repeat colonoscopy because of incomplete examinations or equivocal findings.

\section{DIAGNOSES}

Multiple diagnoses were common, occurring in 38 of the 71 participants $(54 \%)$ and reflecting the high prevalence of diverticular disease $(46 \%)$ and anal lesions $(54 \%)$ concurrent with other pathology (Table 1). Non-participants and dropouts had fewer secondary and tertiary diagnoses as only 25 of 244 subjects had two procedures and the remainder had solely colonoscopy or barium enema. Moreover, a higher proportion of non-participants was categorised as 'normal' suggesting that further investigation was not pursued subsequent to a normal examination or that bleeding had stopped.

\section{TEST PROPERTIES}

The computational formulae for the test properties are illustrated in the Figure. The sensitivity to detect all colonic lesions, excluding diminutive polyps $(<5$ $\mathrm{mm}$ in size, was highest at $\mathbf{0 . 8 0}$ for combined flexible sigmoidoscopy and barium enema. Colonoscopy had a sensitivity of 0.69 , while flexible sigmoidoscopy and double contrast barium enema alone were low at 0.58

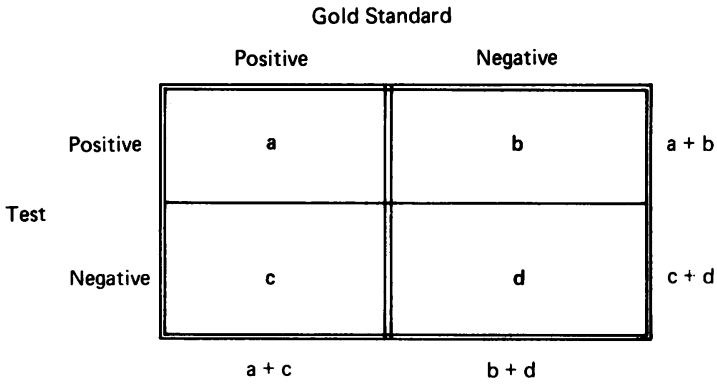

Sensitivity $=a / a+c$

Specificity $=d / b+d$

$p p V=a / a+b$

Likelihood ratio (positive) $=$ sensitivity $/ 1-$ specificity Likelihood ratio (negative) $=1$-sensitivity / specificity Gold Standard $=$ maximum diagnostic data Test $=$ FS, DCBE, CS

Fig. 1 Contingency tables and calculation of test properties.

and 0.50 respectively (Table 2 ). The values for each test property fell minimally when diminutive polyps were included in the analysis and are represented in brackets in Table 3. Colonoscopy yielded the highest specificity 0.78 , positive predictive value 0.87 , and likelihood ratio for a positive test 3.14 (Table 2).

Disease specific sensitivities for each of the diagnostic tests is depicted in Table 4. Colonoscopy was more sensitive for the diagnosis of neoplasia - that is, polyp or cancer, and angiodysplasia in contrast with combined sigmoidoscopy and barium enema which bettered colonoscopy for the evaluation of diverticular disease. Both diagnostic approaches were comparable in the remaining disease categories.

\section{EXAMINATION COMPLETENESS AND} COMPLICATIONS

The caecum or terminal ileum was reached in 70 $(99 \%)$ at barium enema and in $59(83 \%)$ at colonoscopy. The hepatic flexure or ascending colon was reached in an additional nine (total $96 \%$ ) at colonoscopy. Three subjects were examined endoscopically to the sigmoid colon because of a stenosing carcinoma in two (barium enema also failed in one) and

Table 2 Test properties: all diagnoses

\begin{tabular}{lllllll}
\hline Test & Sens & Spec & $P P V$ & $N P V$ & $L R(+)$ & $L R(-)$ \\
\hline FS & 0.58 & 0.67 & 0.82 & 0.35 & 1.76 & 0.63 \\
DCBE & 0.50 & 0.67 & 0.87 & 0.35 & 1.52 & 0.75 \\
FS/BE & 0.80 & 0.56 & 0.81 & 0.56 & 1.82 & 0.36 \\
CS & 0.69 & 0.78 & 0.87 & 0.54 & 3.14 & 0.40 \\
\hline
\end{tabular}

Sens $=$ sensitivity Spec $=$ specificity; $P P V=$ positive predictive value; $N P V=$ negative predictive value; $\operatorname{LR}(+)=$ likelihood ratio (positive result); $\operatorname{LR}(-)=$ likelihood ratio (negative result). 
Table 3 Test properties: all diagnoses

\begin{tabular}{lll}
\hline Test & Sensitivity & Positive predictive value \\
\hline FS & $0 \cdot 58(0 \cdot 57)$ & $0 \cdot 82(0 \cdot 81)$ \\
DCBE & $0 \cdot 50(0 \cdot 43)$ & $0 \cdot 87(0 \cdot 84)$ \\
FS/DCBE & $0 \cdot 80(0 \cdot 77)$ & $0 \cdot 81(0 \cdot 79)$ \\
CS & $0 \cdot 69(0.67)$ & $0 \cdot 87(0 \cdot 86)$ \\
\hline
\end{tabular}

$\mathrm{FS}=$ flexible sigmoidoscopy $; \mathrm{DCBE}=$ double contrast barium enema; $C S=$ colonoscopy; ( $)=$ includes diminutive polyps $<5 \mathrm{~mm}$.

equipment failure in one. The mean insertion for flexible sigmoidoscopy was $54 \mathrm{~cm}$ while $70 \%$ of subjects had insertion to $60 \mathrm{~cm}$.

Suboptimal examinations, defined as at least one segment of bowel poorly seen occurred in $30 \%$ of patients at colonoscopy and $18 \%$ at sigmoidoscopy plus barium enema. Inadequate bowel cleansing was the most common cause of poor examination for all three tests.

One major complication was encountered for each method of investigation. One patient had a mycocardial infarction after bowel preparation for the sigmoidoscopy barium enema combination. A second patient who had a $4 \mathrm{~cm}$ villous adenoma in the transverse colon experienced haemorrhage requiring a blood transfusion and hospitalisation overnight after piecemeal polypectomy. Minor complications that is, vasovagal, overdistension, tachycardia, and phlebitis occurred in six patients for both investigations.

\section{Discussion}

Rectal bleeding, a symptom present in about $15 \%$ of the general population ${ }^{12}$ predicts left sided colonic neoplasia in $8 \%$ to $25 \%$ of individuals when mixed in the stool or present in the toilet water. ${ }^{26}$ Gastroenterologists are no better at predicting neoplasia than general practitioners in these subjects based

Table 4 Sensitivity by disease category

\begin{tabular}{lllll}
\hline Test & $C S$ & $D C B E+F S$ & $D C B E$ & $F S$ \\
\hline Neoplasm & $0.93(0.82)$ & $0.79(0.73)$ & $0.77(0.47)$ & $0.64(0.49)$ \\
Cancer & 1.0 & 0.83 & 0.83 & 0.67 \\
Adenoma & $0.96(0.77)$ & $0.71(0.60)$ & $0.58(0.32)$ & $0.33(0.32)$ \\
DD & 0.50 & 0.94 & 0.84 & 0.53 \\
Anal & 0.75 & 0.81 & 0.11 & 0.78 \\
AVM & 1.0 & 0.33 & 0 & 0.33 \\
IBD & 0.83 & 0.83 & 0.33 & 0.67 \\
Misc & 0.29 & 0.29 & 0.29 & 0.14 \\
Overall & 0.67 & 0.77 & 0.43 & 0.56 \\
\hline
\end{tabular}

$\mathrm{DD}=$ diverticular disease $; \mathrm{AVM}=$ angiodysplasia $; \mathrm{IBD}=$ inflammatory bowel disease; Misc $=$ miscellaneous; ()$=$ including diminutive polyps $<5 \mathrm{~mm}$. upon history and proctoscopy. ${ }^{27}$ Thus, colonic investigation is mandatory in most patients.

In our study population, a final diagnosis of adenoma or carcinoma occurred in $34 \%$ of patients, yielding a pretest probability or disease prevalence of neoplasia of 0.34 . This figure is likely an overestimate because only $25 \%$ of all eligible subjects had neoplasia. Some polyps or cancers could have been missed in non-participants, however, who had only one diagnostic test placing the true prevalence figure somewhere between $25 \%$ and $34 \%$.

Previous reports suggest that of subjects with rectal bleeding, $20 \%$ have anal lesions alone, $25 \%$ have clinically important lesions, $25 \%$ clinically important plus anal lesions and $30 \%$ have no cause identified. ${ }^{2+9}$ In our study only $13 \%$ of patients were considered 'normal', with no source of bleeding identified; $37 \%$ had concommitant anal and clinically important disease and; $33 \%$ had at least one clinically important bleeding lesion. Anal lesions (haemorrhoids, fissures, tears) and diverticular disease were prevalent in $54 \%$ and $46 \%$ of patients respectively. These were the most clinically important diagnoses in only $17 \%$, however, (12/71) and $25 \%$ (18/71) respectively, and most patients had other sources of bleeding. This emphasises the danger of assuming that haemmorrhoids or diverticulosis is responsible for bleeding without undertaking full colonic investigation. Furthermore, the diagnostic return greater than anticipated implies delivery of high quality diagnostic colonic imaging, radiologic and endoscopy, at our institution. Poor quality radiology cannot be compared with high quality endoscopy or vice versa as has been the practice in the previous literature. Thus, generalisation of our results is appropriate only after consideration of local resources, expertise, and population characteristics.

The value of the diagnostic test properties sensitivity, specificity and predictive values, illustrated in the Figure, is becoming increasingly familiar to clinicians. Less familiar, perhaps, is the likelihood ratio which gives the 'odds' that a particular result would have come from a patient with as opposed to a patient without the disease. Likelihood ratios, useful for application in individual patients, are not disease prevalence dependent as are predictive values. ${ }^{28}$ Colonoscopy had the highest likelihood ratio of $3 \cdot 14$ reflecting its high sensitivity and specificity.

The sensitivity of combined flexible sigmoidoscopy plus double contrast barium enema for all lesions was greatest at $\mathbf{0 . 7 8}$. This is largely because of the better sensitivity of the barium enema for diverticular disease, and the high prevalence in our population. Second, as flexible sigmoidoscopy and barium enema were performed first, mild inflammation or anal fissures could have healed before colonoscopy. 
Third, most individuals who undergo colonoscopy have had previous proctosigmoidoscopy and examiners may be less precise in reporting perianal disease, an important proportion of the diagnoses. This is supported by the higher sensitivity of flexible sigmoidoscopy for anal lesions of 0.78 in Table 4 . Finally, the sensitivity of flexible sigmoidoscopy or barium enema individually is low. These results reestablish, that double contrast barium enema cannot stand alone against colonoscopy because of changes in image perception in the presence of diverticular disease and the effects of redundant sigmoid loops and residual stool. ${ }^{29}{ }^{30}$ When we examined our barium enema errors, most occurred in the rectum and sigmoid colon.

For diagnosis of adenoma, carcinoma, and angiodysplasia, colonoscopy is clearly more sensitive than sigmoidoscopy and barium $x$-ray. This is supported by Williams et al who compared a faecal occult blood test, rigid sigmoidoscopy, flexible sigmoidoscopy, double contrast barium enema and colonoscopy in 330 patients with a previous history of adenomas. ${ }^{31}$ Their results showed a sensitivity of $\mathbf{0 . 9 2}$ for colonoscopy, 0.71 for double contrast barium enema and 0.54 for flexible sigmoidoscopy for cancer or polyp detection. Only lesions $\geq 7 \mathrm{~mm}$ were assessed, however, and data for combined sigmoidoscopy and enema could not be extracted from their results. When we adjusted our own data for cancer or adenoma detection and excluded polyps ( $<5 \mathrm{~mm}$, the sensitivity of colonoscopy increased from 0.82 to 0.93 and for flexible sigmoidoscopy and barium enema from 0.73 to 0.79 .

Richter et al and Howard et al have previously established that angiodysplasia is best diagnosed at colonoscopy. ${ }^{32}{ }^{33}$ Although there were only three cases in our study, as expected with this flat mucosal lesion, none were detected by barium enema. In contrast, barium enema alone or with flexible sigmoidoscopy is superior for detecting diverticular disease with a sensitivity of 0.91 , a finding previously reported qualitatively in at least three studies. ${ }^{816}{ }^{22}$ Thus, in the older patient, only when neoplasm or angiodysplasia has been ruled out or active bleeding is directly observed at flexible sigmoidoscopy should the clinician be confident of the diagnosis of diverticulosis or anal disease as the source of blood loss. Other lesions such as inflammatory bowel disease appear equally well demonstrated by either diagnostic approach in this study although our numbers were small.

Complications and side effects of endoscopy and radiology were comparable in both incidence and severity. The haemorrhage after colonoscopy was secondary to a therapeutic intervention, an additional benefit of colonoscopy. While complications have been well recognised for diagnostic and therapeutic colonoscopy, ${ }^{334}$ they appear to have been under-reported for double contrast barium enema. ${ }^{3536}$ Thus, further scrutiny is justified for complications and side effects of the barium enema.

Finally, we have shown that examination of the bowel is more frequently optimal and complete with the signmoidoscopy, barium enema combination. Elderly or debilitated subjects are less capable of manoevering on the $x$-ray table to give high quality barium studies. ${ }^{37}{ }^{38}$ This group was excluded by design from our study to permit unbiased evaluation of all tests. Initial colonoscopy is the investigation of choice in such individuals supplemented by double contrast barium enema if the examination is incomplete or suboptimal.

Applying the results of this study and a review of the literature, we have derived a logical approach to the investigation of the patient with rectal bleeding. Indications for colonoscopy to be the primary investigation would be the presence of any high risk factor for colonic neoplasia; age $\geq 70$ years, as the quality of barium enema falls; sick or debilitated patients in whom high quality double contrast enema is difficult to obtain; lack of locally available high quality radiology; or persistent symptoms despite a negative double contrast barium enema and flexible sigmoidoscopy.

Combined flexible sigmoidoscopy and double contrast barium enema is the appropriate choice in individuals who have no risk factors for neoplasia; under age 70 and physically fit; access to good quality radiology; and finally individuals with persistent symptoms despite negative colonoscopy.

This research was supported by Health and Welfare Canada NHRDP Grant \#6606-2974 and was presented at the American Gastroenterological Association meeting in Chicago, May 1987. Dr E J Irvine was supported by the Ontario Ministry of Health while completing this work. The authors would like to acknowledge and thank Drs $\mathrm{R}$ Rossman and $\mathrm{R}$ Goodacre, consultant gastroenterologists at McMaster University Medical Centre for contributing patients to and completing data forms for this study.

\section{References}

1 Dent OF, Goulston KJ, Zubrzycki J, Chapuis PH. Bowel symptoms in an apparently well population. Dis Colon Rectum 1986; 29: 243-7.

2 Chapuis PH, Goulston KJ, Dent OF, Tait AD. Predictive value of rectal bleeding in screening for rectal and sigmoid polyps. $\mathrm{Br}$ Med J 1985; 290: 1546-8.

3 Staniland JR, Ditchburn J, deDombal FT. Clinical 
presentation of diseases of the large bowel - A detailed study of 642 patients. Gastroenterology 1976; 70: 22-8.

4 Thoeni RF, Venbrux AC. The value of colonoscopy and double-contrast barium enema examination in the evaluation of patients with sub acute and chronic lower intestinal bleeding. Radiology 1983; 140: 603-7.

5 Tedesco FJ, Waye JD, Rasin JB. Colonoscopic evaluation of rectal bleeding: a study of 304 patients. Ann Intern Med 1978; 89: 907-9.

6 Knutson CO, Max MH. Value of colonoscopy in patients with rectal blood loss unexplained by rigid proctosigmoidoscopy and barium contrast enema examinations. Am J Surg 1979; 139: 84-7.

7 Winawer SJ, Leidner SD, Boyle C, Kurtz RC. Comparison of flexible sigmoidoscopy with other diagnostic techniques in the diagnosis of rectocolon neoplasia. Dig Dis Sci 1979; 24: 277-81.

8 Bat L, Pines A, Rabau M, Niv Y, Shemesh E. Colonoscopic findings in patients with hemorrhoids, rectal bleeding and normal rectoscopy. Israel J Med Sci 1985; 21: $139-41$.

9 Rex DK, Lehman GA, Lappas JC, Miller RE. Sensitivity of double contrast barium study for left colon polyps. Radiology 1986; 158: 69-72.

10 Wolff WI, Shinya H, Geffen A, Ozoklay S, Debeer RR. Comparison of colonoscopy and the contrast enema in 500 patients with colorectal disease. Am J Surg 1975; 129: $181-6$.

11 Kaude JV, Harty RF. Sensitivity of single contrast barium enema with regard to colorectal disease as diagnosed by colonoscopy. Eur J Radiol 1982; 2: 290-2.

12 Ott DJ, Gelfan DW, Wu WC, Kerr RM. Sensitivity of double contrast barium enema: Emphasis on polyp detection. AJR 1980; 135: 327-30.

13 Leinecke JL, Dodds WJ, Hogan WJ, Stewart ET. A comparison of colonoscopy and roentganography for detecting polypoid lesions of the colon. Gastrointest Radiol 1977; 2: 125-8.

14 Thoeni RF, Venbrux AC. The value of colonoscopy and double contrast barium enema examination in the evaluation of patients with sub-acute and chronic lower intestinal bleeding. Radiology 1983; 140: 603-7.

15 Spencer RJ, Wolff BG, Ready RI. Comparison of the rigid sigmoidoscope in conjunction with colon $\mathrm{X}$-ray for detection of lesions of the colon and rectum. Dis Colon Rectum 1983; 26: 653-55.

16 Gilbertsen VA, Williams SE, Chuman L, McHugh R. Colonoscopy in the detection of the carcinoma of the intestine. Surg Gynecol Obstet 1979; 149: 877-88.

17 Waye JD. Colonoscopy in rectal bleeding. S Afr J Surg 1976; 14: 143-9.

18 Shinya H, Cwern M, Wolf G. Colonoscopic diagnosis and management of rectal bleeding. Surg Clin N Am 1982; 62: 897-903.

19 Leicester RJ, Hawley PR, Pollett WG, Nicholls RJ. Flexible fiberoptic sigmoidoscopy as an outpatient procedure. Lancet 1982; i: 34-5.

20 Williams CB, Macrae FA, Bartram CI. A perspective study of diagnostic methods in adenoma follow-up. Endoscopy 1982; 14: 74-8.
21 Winthrop JD, Balfe DM, Shackelford GD, McAlister WH, Rosenblum JL, Siegel MJ. Ulcerative and granulomatous colitis in children. Comparison of double and single contrast studies. Radiology 1985; 154: 657-60.

22 Tedesco FJ, Gottfried EB, Corless JK, Brownstein RE. Prospective evaluation of hospitalized patients with non-active lower intestinal bleeding - Timing and role of barium enema in colonoscopy. Gastrointest Endosc 1984; 30: 281-3.

23 Laufer I. Double contrast enema: Technical aspects. In: Laufer I, ed. Double contrast gastrointestinal radiology. Philadelphia: Saunders, 1979.

24 Waye JD. Colonoscopy intubation techniques without fluoroscopy. In: Hunt RH, Way JD, eds. Colonoscopy. London: Chapman and Hall, 1981: 147-78.

25 Irvine EJ, Hunt RH, Stevenson GW, Frost RA, O'Connor J. A comparison of costs of performing double contrast barium enema plus flexible sigmoidoscopy vs colonoscopy to examine the large bowel. Gastroenterology 1987; 92: 1448.

26 Silman AJ, Mitchell P, Nicholls RJ, et al. Self-reported dark red bleeding as a marker comparable with occult bolld testing in screening for large bowel neoplasms. $\mathrm{Br}$ J Surg 1983; 70: 721-4.

27 Goulston KJ, Cook I, Dent OF. How important is rectal bleeding in the diagnosis of polyps and bowel cancer? Lancet 1986; ii: 261-5.

28 Sackett DL, Haynes RB, Tugwell PX. Clinical epidemiology: a basic science for clinical medicine. Boston, Mass: Little Brown, 1985: 59-138.

29 Baker SR, Alterman DD. False negative barium enema in patients with sigmoid cancer and coexistent diverticula. Gastrointest Radiol 1985; 10: 171-3.

30 Dodd GD. The air contrast barium enema/indications and validity. Prog Clin Biol Res 1985; 186: 133-49.

31 Richter J, Hedberg SE, Athanasoulis CA, Schapiro RH. Angiodysplasia - Clinical presentation and colonoscopic diagnosis. Dig Dis Sci 1984; 29: 481-5.

32 Howard OM, Buchanan JD, Hunt RH. Angiodysplasia of the colon. Lancet 1982; ii: 16-9.

33 Ghazi A, Grossman M. Complications of colonoscopy and polypectomy. Surg Clin of North Am 1982; 62: 88996.

34 Macrae FA, Tan KG, Williams CB. Towards safer colonoscopy: A report on the complications of 5,000 diagnostic or therapeutic colonoscopies. Gut 1983; 24: 376-83.

35 Masel H, Masel JP, Casey KV. A survey of colon examination technique in Australia and New Zealand with a review of complications. Australas Radiol 1971; 15: $140-7$.

36 Seaman WB, Wells WJ. Complications of the barium enema. Gastroenterology 1965; 48: 728-37.

37 Wolf EL, Frager D, Beneventano T. Feasibility of double-contrast barium enema in the elderly. AJR 1986; 145: 47-8.

38 Ott DJ, Chen YM, Gelfand DW, Wu WC, Munitz HA. Single contrast versus double contrast barium enema in the detection of colonic polyps. AJR 1986; 146: 993-6. 